\title{
Tracking the PM2.5 inventories embodied in the trade among China, Japan and Korea
}

Yiyi Ju*

\author{
*Correspondence: \\ ju.yiyi@k.mbox.nagoya-u.ac.jp \\ Nagoya University, Nagoya, \\ Aichi, Japan
}

\begin{abstract}
Due to its long-term negative health effects and increasing emissions, the PM2.5 issue has caused rising concerns in recent years. Although official media from East Asian countries tend to avoid blaming PM emission sources on their neighboring countries, researches have proved the existence of pronounced long-range trans-boundary particulate matters transported by nature force and by human activities. In this context, this paper included the structural path analysis (SPA) to quantify trans-boundary PM2.5 at sector level, track its transaction paths and figure out the linkages between consumption and production responsibilities of China, Japan and Korea. Based on the results and policy reviews of current environmental cooperation mechanisms, this paper found that: Considering the China-Japan and China-Korea trades, China's net exportation of embodied PM2.5 emissions has exceeded the importation rates over 10 times (CHN $\rightarrow$ JPN, 56.53 kt, JPN $\rightarrow$ CHN, 3.58 kt; CHN $\rightarrow$ KOR, 59.19 kt, KOR $\rightarrow$ CHN, $5.31 \mathrm{kt})$. Japan and Korea benefited from importing raw materials with high emission intensity from China to meet domestic consumption needs and keep a low national emission level. China, the largest emitter in the world, should first take the responsibility to mitigate its huge domestic PM2.5 emission. However, the relocated emissions from its neighboring countries should not be ignored. For Japan or Korea, due to the close economic interdependence and geographical position, any contribution to the reduction of the trans-boundary emissions or to the solution of atmosphere problems within China also helps those countries themselves. In the long run, all three countries would benefit from enhancing subregional environmental cooperation.
\end{abstract}

Keywords: Trans-boundary air pollutants, PM2.5 embodied in the trade, Responsibility contribution, Regional environmental corporation

\section{Background}

A particulate matter with a mean aerodynamic diameter of $2.5 \mu \mathrm{m}$ or less (WHO 2006), PM2.5 has raised close attention in East Asia due to its long-term negative health effects compared to other larger particles, in addition to the rapid growth of its presence in the past few years. In China, the largest emitter in the world, even though the government has made some achievements in monitoring and mitigating PM2.5 emissions, the endless haze still caused wide-ranged panic among its residents, particularly during winter 
times. Beijing is implementing the strictest regulation measures with great conviction, especially after COP $21 .^{1}$ However, PM2.5 is not only an internal issue.

PM can be transported among neighboring countries. Although official media tend to avoid blaming PM sources on neighboring countries for prudential sake, researches have proved the existence of pronounced long-range trans-boundary particulate matters transported by nature forces, in the case of aerosols from China to the Korean peninsula (Lee et al. 2013) and PM10 from North Africa and continental Europe to Madrid and Birmingham, respectively (Borge et al. 2007).

In addition to being conveyed by means of nature forces, air pollutants mainly flow across boundaries via human activities, especially by trade. Back in the 1970s, scholars proved that international trade may remove ecologically intensive sectors from developed regions to developing regions with relatively less stringent regulation (Mageet and Ford 1972; Markusen 1975; Pethig 1976; Siebert 1977). After 1992, under the new climate change framework, it was found that certain sectors successfully holding or lowering domestic emissions in developed countries were often the same as those increasing imports of embodied emissions (Kanemoto et al. 2014), and empirical study results (Li et al. 2015) also supported such conclusion. It has been widely understood that transboundary emissions negatively affected all neighbor countries in the aspect of regional welfare, economic development and international relationship. The trilateral transaction of China, Japan and Korea is taken as one representative sample within East Asia.

In history, it is not the first time that human beings are faced with trans-boundary air pollution problems. Early in the 1980s, Europe set up the Convention on Long-range Trans-Boundary Air Pollution (CLRTAP), which was later evaluated as paving the way for extensive and fruitful regional cooperation (Dovland et al. 2004). Moreover, in 1990s, regional cooperation on acid rain control was also actively promoted in Asia. Japan's aid and investment were effective in helping China to control its acid rain spread through official development assistance (Lai et al. 2001). However, the tangible solutions to the trans-boundary PM2.5 issue in East Asia could hardly move on. If compared to those successful experiences in Europe, this situation could be explained to some degree by the lack of actions on key sectors, clear responsibility allocation schemes, practical and efficient subregional cooperation and a strong funding mechanism.

This paper included structural path analysis (SPA) to quantify the trans-boundary PM2.5 at sector level, track the transaction paths and figure out the linkage between consumption and production responsibilities of three countries. Based on these results and policy reviews of current environmental cooperation mechanisms, policy suggestions were listed as what measures should be taken or enhanced in key sectors, who should take the responsibility of trans-boundary PM2.5 and in what field the regional environmental corporation could be improved. At a theoretical level, this paper emphasized the feasibility and significance of applying classic methodologies to analyze emission inventories embodied in the trade, such as input-output analysis, in the PM issue. At a practical level, it called for attention on the subregional cooperation of trans-boundary PM2.5 control and offered brief policy suggestions on sector and financing levels, aiming to 
prevent carbon leakage and trans-boundary acid rain problems observed in the past few decades to occur to PM2.5.

\section{Review}

In East Asian countries, not even a domestic mature monitoring system of PM2.5 has been established for a long time, let alone trans-boundary PM2.5 considering flows by forces of nature or embodied in the trade. An explanation of how PM inventory is defined in the paper and why classic methodologies to estimate emission inventories embodied in the trade could be employed in trans-boundary PM issues is necessary.

PM, or more specifically, PM2.5, similar to $\mathrm{CO}_{2}$, is nearly impossible to be removed from atmosphere by dissolving in the rain like $\mathrm{SO}_{2}$ or $\mathrm{NO}_{x}$, or be captured by technologies with acceptable cost in the real manufacturing processes. Such features make PM2.5 as "inventory" rather than as "periodic pollutant boom" when described as an atmosphere contamination resource. In the meantime, differently from $\mathrm{CO}_{2}, \mathrm{PM}$ inventories directly have a negative impact on the respiratory and circulatory systems and are more easily involved in a visible trans-boundary transaction. Thus, it is highly worth-contributed to analyze PM inventories at sectorial resource level, as well as at regional level. Classic methodologies to estimate carbon emission inventories embodied in the trade, such as MRIO or SPA, are acceptable in PM's case.

Klimont et al. (2016) presented a comprehensive assessment of historical global anthropogenic PM emissions, including mass-based size distribution (PM1, PM2.5 and PM10) and primary carbonaceous aerosols (BC and OC). Takahashi et al. (2014) calculated PM2.5 according to the consumption of BC (black carbon) and OC (organic carbon). Sugiyama et al. (2009) multiplied the estimated energy consumption associated with each fuel type by a PM10 emission factor incorporating the technological level of dust collection in each sector. Meng et al. (2015) implemented the calculation according to three sources of PM2.5, stationary combustion, industrial processes and mobile sources.

This paper employed the concept of "PM2.5 inventories embodied in the trade" to figure out whether PM2.5 has been transacted among East Asian countries by human activities like trade, and how PM2.5 flows are transacted at sectorial level.

\subsection{Literature review}

Previous studies on trans-boundary or trans-regional PM inventories vary in measuring scales and final conclusions (Table 1).

This paper aimed to analyze the PM2.5 flows transacted among East Asian countries (China, Japan and Korea) by human activities, like international trade, at sectorial level. Multi-regional input-output model (MRIO) and structural path analysis are reliable methodologies. Few researches have been conducted at the same research scale as this paper.

\subsection{Policy review}

Unlike the successful cases of in Europe in the 1990s, so far, no solid and regulatory regime has been established in East Asia to solve trans-boundary environmental issues. Despite the high interdependence of economic activities, China, Japan and Korea are 





Table 2 Environmental ODAs from Japan to China (in 100 million JPN yen). Source: Ministry of Foreign Affairs of Japan

\begin{tabular}{lrrllllllll}
\hline & $\mathbf{2 0 0 6}$ & $\mathbf{2 0 0 7}$ & $\mathbf{2 0 0 8}$ & $\mathbf{2 0 0 9}$ & $\mathbf{2 0 1 0}$ & $\mathbf{2 0 1 1}$ & $\mathbf{2 0 1 2}$ & $\mathbf{2 0 1 3}$ & $\mathbf{2 0 1 4}$ & $\mathbf{2 0 1 5}$ \\
\hline Loan & 1371.28 & 463.02 & - & - & - & - & - & - & - & - \\
Aids & 24.02 & 14.49 & 19.92 & 13.08 & 14.66 & 8.43 & 2.88 & 2.84 & 0.85 & 1.07 \\
Tech & 309.68 & 281.25 & 270.58 & 303.93 & 34.68 & 32.96 & 25.27 & 20.18 & 14.36 & 8.06 \\
\hline
\end{tabular}

still backed up with different authority systems, different levels of economic development and quite intense current relationship. However, instead of a unified regime, each country in East Asia has been participating in various cooperative mechanisms through various channels.

\subsubsection{Bilateral cooperation}

According to Kim (2014), bilateral agreement on environmental cooperation is the main form of environmental cooperation in East Asia (JPN\&KOR, in 1993; CHN\&KOR, in 1993; CHN\&JPN, in 1994).

The bilateral environmental cooperation between Japan and China has been highly evaluated for its large-scale and various forms. Since the 1990s, Japan has provided China with green aids and loans at lower interest rates for environmental projects through ODA (official development assistance) (Table 2).

Bilateral cooperation has been a major channel for Japan to deal with its "concern with and enthusiasm for the acid rain issue" (Lai et al. 2001, 1848) in the 1990s. The total scale has shrunk since 2006, and emphasis was moved from direct financial aids to technology aids. Besides ODAs, forums on greenhouse gas, air pollutants, marine litter, nuclear contamination, illegal trash export problem and other topics also greatly improved the environmental cooperation between Japan and China.

Based on the bilateral agreement signed in 1993, China and Korea further established a regular joint committee in 1994. Regular conferences focused on common concerns as trans-boundary dust storm, pollution abatement of the Huanghai Sea and illegal transport of solid waste. Japan and Korea signed a bilateral agreement in 1993 and established a regular joint committee. It mainly aimed to strengthen the exchange of environmental information, human resources and technology, as well as to improve joint research projects.

\subsubsection{Multilateral cooperation}

East Asian countries began to actively seek multilateral collaborative environment measures in the 1990s.

Joint Research Project on Long-range Transboundary Air Pollutants in North-East Asia (LTP) is a joint research project born in 1994. It was established by China, Japan and Korea aiming to provide scientific information and develop emission reduction scenarios for long-range trans-boundary air pollutants, becoming an international cooperative tool for environmental protection over the North-East Asian region.

Tripartite Environment Ministers Meeting (TEMM) is a tripartite cooperation program consisting of a Minister's meeting, three environmental research institutes and a 
DSS organization. The first meeting was in 1999, and the program aim is to mitigate trans-boundary photochemical oxidant pollution in North-East Asia.

The Acid Deposition Monitoring Network in East Asia (EANET) was established as a regional monitoring network with standardized monitoring methods and analytical techniques regarding the state of acid deposition in Asia in 1998.

North-East Asian Subregional Programme for Environmental Cooperation (NEASPEC) is a comprehensive intergovernmental cooperation framework addressing environmental challenges in North-East Asia. As a follow-up to the United Nations Conference on Environment and Development held in 1992, NEASPEC was established in 1993 by six members: China, Democratic People's Republic of Korea, Japan, Mongolia, Republic of Korea and the Russian Federation-to promote environmental cooperation in the subregion. In 2000, the member states agreed to establish the Core Fund at the Sixth Meeting of Senior Officials to mitigate trans-boundary air pollutants. Korea has been playing an important role of an initiator at various multilateral mechanisms and a strong contributor to NEASPEC (Kim 2014). The contribution to the Core Fund of each country can be viewed in Table 3 .

Other Relevant Multilateral Initiatives are UNEP Project ABC (Atmospheric Brown Clouds) and UNEP Joint Forum on Atmospheric Environment in Asia and the Pacific.

The subregional environmental cooperation in East Asia has made valuable achievements in the past few decades. However, member countries at different development periods hold different appeals of environmental cooperation. Among all the current multilateral cooperation mechanisms of trans-boundary environmental problems, most regulatory mechanisms are still on framework build and research work level. Tangible actions with solid funds to solve trans-boundary PM problems are still lacking. It will take time to reach a solid and regulatory regime with legal force in East Asia. There is still a long way to find appropriate cooperation forms for further and feasible reduction measures, both in the short and the long run.

\section{Model and data}

\subsection{Input-output model}

The input-output model is widely used to link the final output of goods and services to direct air pollutants or green gas emissions through complicated economic activities.

Supposing that one area is divided into $m$ economies and each economy is divided into $n$ industrial sectors, the fundamental equation of the multi-regional input-output

Table 3 Contributions to the Core Fund of the NEASPEC (in thousand US \$). Source: NEASPEC Senior Officials Meeting (SOM) reports, SOM 19

\begin{tabular}{lrrrllllllr}
\hline & $\mathbf{2 0 0 1}$ & $\mathbf{2 0 0 2}$ & $\mathbf{2 0 0 3}$ & $\mathbf{2 0 0 4}$ & $\mathbf{2 0 0 5}$ & $\mathbf{2 0 0 6}$ & $\mathbf{2 0 0 7}$ & $\mathbf{2 0 0 8}$ & $\mathbf{2 0 0 9}$ & $\mathbf{2 0 1 0}$ \\
\hline China & 0 & 0 & 50 & 0 & 49.97 & 49.99 & 49.99 & 49.99 & 49.99 & 50 \\
Japan & 100 & 0 & 72 & 57.6 & 0 & 0 & 0 & 0 & 0 & 0 \\
South Korea & 100 & 100 & 0 & 100 & 0 & 100 & 100 & 100 & 0 & 100 \\
Russia & 0 & 0 & 0 & 0 & 0 & 0 & 0 & 0 & 75 & 0 \\
Mongolia & 0 & 0 & 0 & 0 & 0 & 0 & 0 & 0 & 0 & 0 \\
North Korea & 0 & 0 & 0 & 0 & 0 & 0 & 0 & 0 & 0 & 0 \\
\hline
\end{tabular}


(MRIO) model links the $m n \times 1$ final demand vector $\mathbf{y}$ with the $m n \times 1$ total output vector $\mathbf{x}$ via

$$
\mathbf{x}=(\mathbf{I}-\mathbf{A})^{-1} \mathbf{y}=\mathbf{L y},
$$

where $\mathbf{I}$ is the identity matrix; $\mathbf{A}$ is the $m n \times m n$ matrix of intermediate use coefficient; $\mathbf{y}$ is the total final demand including household final consumption, nonprofit institutions serving households, government final consumption, gross fixed capital formation, changes in inventories, acquisitions-less disposals of valuables and other balance items; $\mathbf{L}$ is the $m n \times m n$ Leontief inverse matrix, which displays all direct and indirect uses in one sector required by a unit of final output from another sector.

Chains of intermediate uses can be traced through layers of a production system instigated by final demand via SPA model (Waugh 1950; Miller and Blair 2009). Thus, this paper utilized SPA model to figure out all inter-regional and inter-sectoral paths in all production steps. This is achieved by unraveling the Leontief inverse matrix using its power series approximation.

$$
\mathbf{x}=(\mathbf{I}-\mathbf{A})^{-\mathbf{1}} \mathbf{y}=\mathbf{I}+\mathbf{A}+\mathbf{A}^{2}+\mathbf{A}^{3}+\cdots{ }_{t \rightarrow \infty} \mathbf{A}^{t}
$$

Then this paper adopted the $1 \times m n$ direct PM2.5 emission coefficient vector $\mathbf{e}^{\mathrm{d}}$. The $1 \times m n$ embodied PM2.5 emission coefficient vector e represents the emission intensity of each sector including all direct and indirect emissions.

$$
\mathbf{e}=\mathbf{e}^{d} \mathbf{L}=\left(\left(\mathrm{e}_{1}^{\mathrm{d}^{1}} / x_{1}^{1} \cdots e_{n}^{\mathrm{d}^{1}} / x_{n}^{1}\right) \cdots\left(e_{1}^{d^{m}} / x_{1}^{m} \cdots e_{n}^{d^{m}} / x_{n}^{m}\right)\right)(\mathbf{I}-\mathbf{A})^{-\mathbf{1}}
$$

Or another measure form of $\mathbf{e}$ as $\mathbf{E}$

$$
\mathbf{E}=\hat{\mathbf{e}}^{d} \mathbf{L}=\hat{\mathbf{e}}^{d}(\mathbf{I}-\mathbf{A})^{-1}
$$

where $\hat{\mathbf{e}}^{d}$ means the diagonal matrix of $\mathbf{e}^{d}$.

If post-multiply $\mathbf{e}$ by the total output $\mathbf{x}$, all paths showing how embodied PM2.5 emissions are transported among sectors and regions in each production step could be reached.

$$
\mathbf{f}=\mathbf{e x}=\mathbf{e}(\mathbf{I}-\mathbf{A})^{-1} \mathbf{y}
$$

\subsection{Structural path analysis}

The structural path analysis (SPA) provides the access to identify the inter-sector and inter-regional flows of embodied PM2.5 thus tracking the final consumption attribution path back to the production network. The SPA performed in this paper is based on Eq. (5).

$$
\mathbf{f}=\mathbf{e x}=\mathbf{e}(\mathbf{I}-\mathbf{A})^{-1} \mathbf{y}=\mathbf{e y}+\mathbf{e A y}+\mathbf{e A}^{2} \mathbf{y}+\mathbf{e A}^{3} \mathbf{y}+\cdots
$$

The embodied PM2.5 emission $\mathbf{f}$ consists of the direct contribution ey from the initial production process, Step 0; and the indirect contribution from intermediate requirements and feedback effects in the supply chain, eAy for Step 1, $\mathbf{e A}^{2} \mathbf{y}$ for Step 2, $\mathbf{e A}^{3} \mathbf{y}$ for Step 3, and so on. Full expansion could be viewed more clearly as Skelton et al. (2011) illustrated in 2011 in Table 4. 
Table 4 All emission paths of PM2.5 emission from production to consumption attribution. Source: Skelton et al. (2011)

\begin{tabular}{|c|c|c|c|}
\hline$i, j, k \in\{1,2, \ldots, m n\}$ & To sector in step 0 & To sector in step 1 & To sector in step 2 \\
\hline From sector in Step 1 & $f_{j i}^{1 \rightarrow 0}=e_{j} A_{j i} y_{i}$ & - & - \\
\hline From sector in Step 2 & $f_{k j i}^{2 \rightarrow 0}=e_{k} A_{k j} A_{j i} y_{i}$ & $f_{k j}^{2 \rightarrow 0}=e_{k} A_{k j} \mathbf{A}_{j:} \mathbf{y}$ & - \\
\hline From sector in Step 3 & $f_{l k j i}^{3 \rightarrow 0}=e_{l} A_{l k} A_{k j} A_{j i} y_{i}$ & $f_{l k j}^{3 \rightarrow 1}=e_{l} A_{l k} A_{k j} \mathbf{A}_{j:} \mathbf{y}$ & $f_{l k}^{3 \rightarrow 2}=e_{/} A_{l k} \mathbf{A}_{k:} \mathbf{y}$ \\
\hline
\end{tabular}

where $f_{j i}^{1 \rightarrow 0}$ measures emissions from all sectors embodied in the output of sector $j$ at Step 1 purchased by sector $i$ at Step $0 ; f_{k j i}^{2 \rightarrow 0}$ measures emissions from all sectors embodied in the output of sector $k$ at Step 2 purchased by sector $j$ at Step 1 to meet final demand requirements from sector $i$ at Step $0 ; f_{l k i i}^{3 \rightarrow 0}$ measures emissions from all sectors embodied in the output of sector $I$ at Step 3 purchased by sector $k$ at Step 2 and originally purchased by sector $j$ at Step 1 to meet final demand requirements from sector $i$ at Step 0; and similar measure for the remaining paths

It has been a long way debating on who should take the responsibility of embodied emissions and what kind of principle or allocation plan should be adopted globally in the case of greenhouse gases. Neither full producer responsibility nor full consumer responsibility is accepted as fair (Table 5 , Spencer 2007).

This paper regards trans-boundary PM as a similar case. One of the essential concepts of the IO theory is to provide the access to illustrate the circular flows of commodities and money between final consumption attributions and production attributions via the power series approximation expansion of SPA. In this way, Lenzen and Murray conceptualized the emission responsibility by illustrating the linkage emission paths between final production and consumption attributions, or, in other words, the respective downstream and upstream responsibilities (Lenzen and Murray 2010). For example, $\mathrm{fc}_{l}^{3}$ measures the PM2.5 emissions from all sectors at upper production steps induced by sector $l$ at Step 3, thus indicating its upstream consumption attributions; $\mathrm{fp}_{l}^{3}$ measures the PM2.5 emissions from all sectors at Steps 1 and Step 2, enabling the verification of the emission of sector $l$ at Step 3, which indicates the downstream production attributions. In this way, how emission responsibility is linked from the production side and consumption side could be clearly illustrated. Regardless of whether it is based on production or consumption accounting, the final aggregated attribution equals to each other.

\subsection{Data sources}

Fiscal year 2010 was selected as objective year and 2005 as basic year.

The input-output tables of 2005 and 2010 were collected from the world input-output table compiled by the World Input-Output Database (WIOD), in 56 sectors and 43 countries. Table 6 shows the structure of the re-compiled input-output tables.

Table 5 Emission attribution for consumption and production side. Source: Skelton et al. (2011)

\begin{tabular}{|c|c|c|}
\hline$i, j, k \in\{1,2, \ldots, m n\}$ & Consumption attribution & Production attribution \\
\hline Step 0 (final attribution) & $\mathrm{fc}_{i}^{0}=e_{i} y_{i}$ & $\mathrm{fp}_{i}^{0}=\mathbf{E}_{i: \mathbf{y}}$ \\
\hline Step 1 & $\mathrm{fc}_{j}^{1}=e_{j} \mathbf{A}_{j: \mathbf{y}}$ & $\mathrm{fp}_{\mathrm{j}}^{\prime}=\mathbf{E}_{j:} \mathbf{A y}$ \\
\hline Step 2 & $\mathrm{fc}_{k}^{2}=e_{k} \mathbf{A}_{k}: \mathbf{A y}$ & $\mathrm{fp}_{k}^{2}=\mathbf{E}_{k}: \mathbf{A}^{2} \mathbf{y}$ \\
\hline Step 3 & $\mathrm{fc}_{l}^{3}=e_{l} \mathbf{A}_{/:} \mathbf{A}^{2} \mathbf{y}$ & $\mathrm{fp}_{l}^{3}=\mathbf{E}_{/:} \mathbf{A}^{3} \mathbf{y}$ \\
\hline
\end{tabular}


Table 6 Trilateral input-output table of China, Japan and Korea

\begin{tabular}{|c|c|c|c|c|c|c|}
\hline \multirow[t]{2}{*}{ Intermediate input } & \multicolumn{4}{|c|}{ Intermediate demand } & \multicolumn{2}{|c|}{ Final demand } \\
\hline & $\mathrm{CHN}$ & JPN & KOR & ROW & $y$ & $x$ \\
\hline \multicolumn{7}{|l|}{$\mathrm{CHN}$} \\
\hline \multicolumn{7}{|l|}{ JPN } \\
\hline \multicolumn{7}{|l|}{ KOR } \\
\hline \multicolumn{7}{|l|}{ ROW } \\
\hline \multicolumn{7}{|l|}{ Value added } \\
\hline$x$ & & & & & & \\
\hline
\end{tabular}

Table 7 Integrated sectors in this paper

\begin{tabular}{|c|c|c|c|c|c|}
\hline No. & Abbreviation & Sector & No. & Abbreviation & Sector \\
\hline 1 & $A G$ & Agriculture & 9 & M_TR & Transport equipment \\
\hline 2 & PW & Supply of power, heat and water & 10 & M_MF & Manufacture \\
\hline 3 & MN & Mining and quarrying & 11 & $\mathrm{CT}$ & Construction \\
\hline 4 & FU & Fuels and coke & 12 & $\mathrm{TR}$ & Transport \\
\hline 5 & M_MT & Metals & 13 & WH & Warehousing \\
\hline 6 & M_NM & Nonmetallic mineral products & 14 & $\mathrm{RC}$ & Recycle \\
\hline 7 & M_CH & Chemical products & 15 & CM & $\begin{array}{l}\text { Commercial and scientific } \\
\text { activities }\end{array}$ \\
\hline 8 & M_PP & $\begin{array}{l}\text { Paper products and publishing } \\
\text { activities }\end{array}$ & 16 & RS & Residential activities \\
\hline
\end{tabular}

All data were re-complied into 16 sectors listed in Table 7. Their integration process was listed in Additional file 1.

The PM2.5 emission data of 2005 and 2010 were employed from GAINS-ASIA database in 82 sectors under the ECLIPSE_V5a_CLE_base scenario, which refers to a reference case for all countries under current legislation for each country (IIASA 2008a, b). GAINS model database estimates PM2.5 concentrations at 1875 air quality monitoring stations located in diverse environments ranging from remote background locations to busy street canyons (Kiesewetter et al. 2015). PM emission sources are distinguished according to residential sector (from family lightning, three-stone, fireplace, household boiler and medium boiler), kerosene lamps, diesel generators, transport (from specific vehicle types, together with international shipping and aviation), large-scale combustion, industry (from coke production, brick kilns and gas flaring for over ten sectors), agriculture waste burning and waste. GAINS database is employed as part of the standard modeling framework for negotiations under the CLRTAP and the United Nations Framework Convention on Climate Change (UNFCCC).

\section{Results}

\subsection{Accurate amount of the trans-boundary PM2.5}

The Sankey diagram is a specific type of flow diagram, in which the width of the arrows is shown proportionally to the flow quantity by production steps. It is widely used for visualizing energy balances and material flows. Figure 1 is the Sankey diagram of PM2.5 


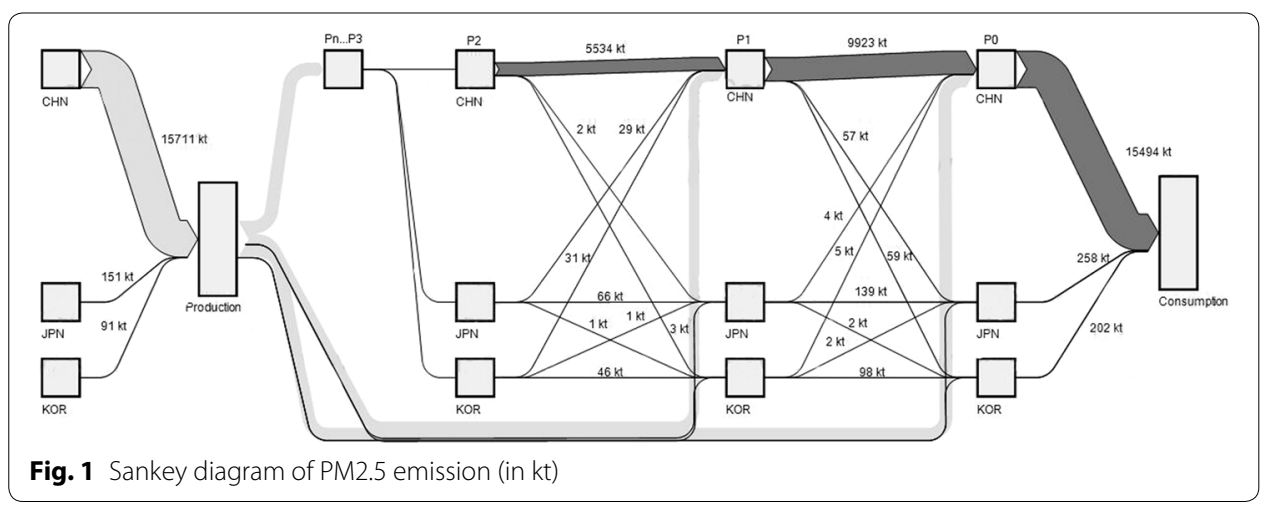

emission flows among China, Japan and Korea, which provides an overview of the PM2.5 embodied within the subregion.

The right side of the Sankey diagram in Fig. 1 shows the total final consumption of PM2.5, 15,953.17 kt (CHN, 15710.57 kt; JPN, 151.16 kt; KOR, 91.44 kt), comprised of household final consumption, nonprofit institutions serving households, government final consumption, gross fixed capital formation and changes in inventories. From right to left, the dark gray paths indicate the intermediate consumption attributions at Steps $1,2,3$, etc., and how these paths flow across boundaries among China, Japan and Korea. The light gray paths indicate the direct PM2.5 emissions at Step 1, 2, 3, etc., linking back to the production attributions. The emission amount of each arrow is marked out and detailed decomposition by sector and by region would be listed in tables afterward. Finally, the production attribution is shown at the left side of the diagram with a same total amount of 15,953.17 kt PM2.5 (CHN, 15,710.57 kt; JPN, 151.16 kt; KOR, 91.44 kt) as the consumption attribution.

If decomposed by sector, the structure of consumption and production attributions on the two sides of the Sankey diagram could be shown in Table 8 .

The total amount of PM2.5 emission of China in 2010 weighed far more than which of Japan and Korea, nearly a hundred times. In China, differently from the production side, in which embodied PM2.5 were mostly emitted by five sectors including residential activities $(5746.82 \mathrm{kt})$, metals $(3588.18 \mathrm{kt})$, manufacture $(1905.46 \mathrm{kt})$, nonmetallic mineral products $(1811.66 \mathrm{kt})$ and agriculture (1030.05 kt), emissions in the consumption side came out to be more concentrated on three sectors only: residential activities (4999.16 kt), construction (3820.52 kt) and manufacture sector (3438.32 kt). Such difference between production and consumption attribution indicates that although PM2.5 had been discharged in large quantities during the production process of agriculture, and metals and nonmetallic mineral products (which mainly provided raw materials such as steel and cement), these emissions were induced by residential activities to a large extent, for example, by manufacture and construction sectors. If policy makers only focus on domestic production process, the true dominant sources could be ignored. Enhancement of regulation on upstream sectors (residential activities, manufacture and construction sectors) is as important as abatement measures taken on the downstream sectors. 
Table 8 PM2.5 emission (in kt) of production and consumption attribution

\begin{tabular}{llrrrrrr}
\hline No. & Sector & \multicolumn{1}{c}{ CHN_P } & \multicolumn{1}{c}{ CHN_C } & JPN_P & JPN_C & KOR_P & KOR_C \\
\hline 1 & AG & 1030.05 & 498.35 & 27.60 & 9.10 & 6.11 & 2.86 \\
2 & PW & 957.26 & 133.18 & 11.33 & 4.77 & 6.50 & 2.81 \\
3 & MN & 15.90 & 16.52 & 0.01 & 0.01 & 0.01 & 0.00 \\
4 & FU & 33.00 & 27.84 & 0.06 & 0.59 & 0.04 & 0.82 \\
5 & M_MT & 3588.18 & 581.02 & 4.52 & 10.56 & 2.44 & 7.97 \\
6 & M_NM & 1811.66 & 138.28 & 19.92 & 2.63 & 16.58 & 1.89 \\
7 & M_CH & 17.63 & 73.18 & 1.43 & 2.99 & 0.17 & 2.20 \\
8 & M_PP & 10.27 & 9.20 & 0.90 & 0.73 & 0.18 & 1.58 \\
9 & M_TR & 345.66 & 954.62 & 29.34 & 45.42 & 17.91 & 39.71 \\
10 & M_MF & 1905.46 & 3438.32 & 31.32 & 65.26 & 19.00 & 61.12 \\
11 & CT & 58.54 & 3820.52 & 11.09 & 43.97 & 2.38 & 35.66 \\
12 & TR & 45.92 & 109.87 & 0.69 & 3.92 & 0.74 & 2.64 \\
13 & WH & 69.66 & 12.09 & 5.25 & 2.35 & 2.61 & 0.58 \\
14 & RC & 28.96 & 16.81 & 1.56 & 0.13 & 0.00 & 0.37 \\
15 & CM & 45.59 & 665.15 & 4.14 & 25.77 & 0.35 & 12.99 \\
16 & RS & 5746.82 & 4999.16 & 1.99 & 39.32 & 16.40 & 28.36 \\
& Sum & $15,710.57$ & $15,710.57$ & 151.16 & 151.16 & 91.44 & 91.44 \\
\hline
\end{tabular}

In the cases of Japan and Korea, who have been known as highly efficient in fossil fuel consumption and environmental friendly in production process, they shared a quite similar PM2.5 emission structure. The variety of status along the supply chain of these sectors led to the difference of attributions between the production and consumption sides, like China, but with a very small emission amount, even if comparing with other countries. Both Japan and Korea held a large emission in transport equipment sector, which only occupied $2.21 \%$ (or consumption side $6.10 \%$ ) of the total emission in China's case. This is probably because both of the two countries depended heavily on the manufacture of motor vehicles, trailers and other transport equipment. Compared with Japan, PM2.5 emission embodied in the first industry in Korea was smaller partly due to its limited cultivated land and weaker agriculture.

What's more, Japan held a very little amount of production attribution of residential activities, which indicates the highly advanced life pattern and environmental awareness of Japanese residents. Such sustainable life pattern should be followed by China. In the case of China (or other countries with a wide range of territorial land and rich resource inventories), residents do not have enough scientific understanding of saving for the environment or future climate change. Concerns or even panic on PM2.5 spread wide ahead, but residents are not well prepared to undertake all kinds of potential inconveniences that a "greener" life style would bring to them. Thus, only when government's efforts, including reduction achievements in the past and more tangible actions in the future, are announced, residents will cease blaming the responsibility of atmosphere issues on the government and become more willing to rebuild their lifestyles.

If further decomposed by regions, the structure of embodied PM2.5 that flows in the central part of the Sankey diagram could be shown in Table 9.

The total PM2.5 emissions of China induced by the final demand of Japan and Korea were 56.53 and $59.19 \mathrm{kt}$, which contributed 37.40 and $64.73 \%$ of the country's total 
Table 9 Trans-boundary PM2.5 emission among China, Japan and Korea (in kt)

\begin{tabular}{llllllll}
\hline No. & Sector (receiving country) & $\mathbf{J} \rightarrow \mathbf{C}$ & $\mathbf{K} \rightarrow \mathbf{C}$ & $\mathbf{C} \rightarrow \mathbf{J}$ & $\mathbf{K} \rightarrow \mathbf{J}$ & $\mathbf{C} \rightarrow \mathbf{K}$ & $\mathbf{J} \rightarrow \mathbf{K}$ \\
\hline 1 & AG & 0.03 & 0.05 & 0.21 & 0.01 & 0.17 & 0.01 \\
2 & PW & 0.01 & 0.02 & 0.15 & 0.01 & 0.23 & 0.01 \\
3 & MN & 0.00 & 0.01 & 0.00 & 0.00 & 0.00 & 0.00 \\
4 & FU & 0.00 & 0.00 & 0.16 & 0.00 & 0.33 & 0.01 \\
5 & M_MT & 0.07 & 0.08 & 4.07 & 0.18 & 4.11 & 0.14 \\
6 & M_NM & 0.01 & 0.01 & 0.13 & 0.00 & 0.11 & 0.01 \\
7 & M_CH & 0.03 & 0.06 & 0.88 & 0.03 & 0.77 & 0.05 \\
8 & M_PP & 0.00 & 0.00 & 0.13 & 0.00 & 0.44 & 0.01 \\
9 & M_TR & 0.63 & 0.53 & 7.04 & 0.20 & 9.96 & 0.44 \\
10 & M_MF & 1.28 & 2.76 & 17.32 & 0.70 & 21.36 & 0.79 \\
11 & CT & 1.11 & 1.10 & 13.93 & 0.44 & 14.13 & 0.79 \\
12 & TR & 0.03 & 0.03 & 0.95 & 0.03 & 0.33 & 0.02 \\
13 & WH & 0.00 & 0.00 & 0.08 & 0.00 & 0.09 & 0.00 \\
14 & RC & 0.00 & 0.00 & 0.00 & 0.00 & 0.13 & 0.01 \\
15 & CM & 0.12 & 0.24 & 5.23 & 0.17 & 3.64 & 0.07 \\
16 & RS & 0.24 & 0.41 & 6.25 & 0.20 & 3.39 & 0.07 \\
& Sum & 3.58 & 5.31 & 56.53 & 1.98 & 59.19 & 2.42 \\
\hline
\end{tabular}

emissions, respectively. In contrast, emissions flowing from Japan and Korea to China were rather small $(\mathrm{J} \rightarrow \mathrm{C}, 3.58 \mathrm{kt}$; $\mathrm{K} \rightarrow \mathrm{C}, 5.31 \mathrm{kt})$, and for the bilateral flows between Japan and Korea ( $\rightarrow \mathrm{K}, 2.42 \mathrm{kt}$; $\mathrm{K} \rightarrow \mathrm{J}, 1.98 \mathrm{kt}$ ), even smaller. According to this paper, the net trans-boundary PM2.5 from China to Japan and Korea via economic activities was pronounced and affected the total emission level of Japan and Korea to a great extent.

The structures of trans-boundary emissions from China to Japan and from China to Korea were quite similar as they share a similar bilateral trading structure. Total transboundary emissions were dominated by manufacture, construction (including construction machinery), transport equipment, metals, residential activities and commercial and scientific activities sectors, contributing $95.24 \%$ and $95.61 \%$ as a sum, respectively. In these sectors, the trade volume, or in other words, the transaction of goods and services from China to Japan or Korea of construction sector was quite low (JPN, 0.01\%; KOR, $0.00 \%$ ), which indicates that China's domestic high emission intensity of construction led to its high trans-boundary emission. Sectors with a large trade scale were manufacture (JPN, 48.07\%; KOR, 48.70\%), metals (JPN, 17.32\%; KOR, 21.16\%), transport equipment (JPN, 5.87\%; KOR, 3.93\%) and residential activities sectors (JPN, 5.87\%; KOR, 5.35\%), which indicates that the high trans-boundary PM2.5 emission level of these sectors was a result of both high emission intensity of China itself and the large bilateral trade volume from China to Japan or from China to Korea. If China keeps on expanding the bilateral trade volume of these sectors under the efficiency of fossil fuel consumption in 2010, the total PM2.5 emission level in East Asia could be worsened.

\subsection{Responsibilities of the trans-boundary PM2.5}

The detailed top 10 paths of trans-boundary PM2.5 in East Asia are listed in Table 10. 
Table 10 Top 10 paths of trans-boundary PM2.5 emission (in kt)

\begin{tabular}{llc}
\hline Top & Path & PM2.5 \\
\hline 1 & CHN_M_MF $\leftarrow$ CHN_M_MF $\leftarrow$ KOR_M_MF & 4.39 \\
2 & CHN_M_MF $\leftarrow$ CHN_M_MF $\leftarrow$ JPN_M_MF & 3.86 \\
3 & CHN_M_MF $\leftarrow$ KOR_M_MF $\leftarrow$ KOR_M_MF & 3.45 \\
4 & CHN_M_MF $\leftarrow$ JPN_M_MF $\leftarrow$ JPN_RS & 2.39 \\
5 & CHN_M_MT $\leftarrow$ CHN_M_MF $\leftarrow$ KOR_M_MF & 2.33 \\
6 & CHN_M_MF $\leftarrow$ JPN_M_MF $\leftarrow$ JPN_M_MF & 2.31 \\
7 & CHN_M_MT $\leftarrow$ JPN_M_MF $\leftarrow$ KOR_CT & 2.25 \\
8 & CHN_M_MT $\leftarrow$ CHN_M_MT $\leftarrow$ JPN_CT & 2.13 \\
9 & CHN_M_MT $\leftarrow$ CHN_M_MF $\leftarrow$ JPN_M_MF & 2.04 \\
10 & CHN_M_MT $\leftarrow$ CHN_M_MT $\leftarrow$ KOR_CT & 2.00 \\
\hline
\end{tabular}

The path with the largest trans-boundary PM2.5 (4.39 kt) is the one related to emissions from all sectors embodied in the output of China's manufacture sector at Step 3, purchased by China's manufacture sector at Step 2 to meet the final demand requirements from Korea's manufacture sector at Step 0. Not surprisingly, from the production side, the sources of all top 10 paths of trans-boundary PM2.5 emission among the three countries are sectors from China, mainly manufacture (5 paths) and metals (5 paths) sectors. From the consumption side, Korea's manufacture (3 paths), Japan's manufacture (3 paths) and Japan's residential activities sector (1 path) induced most trans-boundary PM2.5 emissions. If viewed considering China separately, in the production process, PM2.5 emissions from construction and supply of power, heat and water sectors were quite large, but these sectors did not participate in trans-boundary PM2.5 emission to a proportional large extent. The high emission level of these sectors was a result of their high domestic emission intensity, rather than the final requirements from Japan or Korea. However, the final requirements of manufacture and residential activities of Japan and Korea induced a robust amount of PM2.5 emission of China's manufacture and metals sector, which contributed significantly to the emission level of Japan and Korea. If measured from the production attribution, these emissions would be relocated and become a part of the responsibility of China. Japan and Korea have been benefited from such emission leakages. The abatement duty of these relocated emissions should be performed both by producers from China and consumers from Japan and Korea. On the other hand, China has been the net importer in China-Japan trade or China-Korea trade, especially in manufacture (JPN, 46.07\%; KOR, 48.20\%) and chemical products sectors (JPN, 13.77\%; 25.06\%). However, few embodied PM2.5 emissions were imported in these two sectors. In order to mitigate the PM2.5 emission in East Asia, China should learn from the existed experience of Japan and Korea, not only by importing the direct emission abatement technology (e.g., more efficient electrostatic precipitator or bag precipitator for boilers to control dust, PM10 and PM2.5), but also by upgrading the current production technology to follow the Japan or Korea pattern in these sectors.

According to this paper, considering the China-Japan and China-Korea trades, China's net exportation rates of embodied PM2.5 emission have exceeded the importation rates over 10 times $(\mathrm{CHN} \rightarrow \mathrm{JPN}, 56.53 \mathrm{kt}$, JPN $\rightarrow$ CHN, $3.58 \mathrm{kt}$; CHN $\rightarrow$ KOR, $59.19 \mathrm{kt}, \mathrm{KOR} \rightarrow \mathrm{CHN}, 5.31 \mathrm{kt})$. Japan and Korea benefited from importing raw 
materials with high emission intensity from China to meet domestic consumption needs and keep a low national emission level. China, the world's largest emitter, should first take the responsibility to mitigate its huge domestic PM2.5 emission. However, the emission leakages it suffered from neighboring developed countries should not be ignored. For Japan and Korea, due to the close economic interdependence and geographical position, any contribution to the reduction of the trans-boundary emissions or to the solution of atmosphere problems within China also helps those countries themselves. In the long run, all three countries would benefit from enhancing subregional environmental cooperation.

\section{Conclusion remarks}

Trans-boundary PM2.5 has been negatively affecting neighboring countries and required tangible regional cooperation. This paper answered the following research questions:

1. How much PM2.5 inventories embodied in the trade have been transacted among East Asia?

PM2.5 can be transported among neighboring countries by forces of nature and via economic activities. The total PM2.5 inventories of China induced by the final demand of Japan and Korea were 56.53 and 59.19 kt, respectively, which affected the total emission level of Japan and Korea to a great extent.

2. Which sectors mainly contributed to the trans-boundary PM2.5 emissions? Who should be responsible for them?

Trans-boundary emissions were dominated by manufacture, construction (including construction machinery), transport equipment, metals, residential activities and commercial and scientific activities sectors.

The final requirements of manufacture and residential activities sectors of Japan and Korea induced a robust amount of PM2.5 emission of China's manufacture and metals sectors (see top 10 trans-boundary PM2.5 paths). The abatement duty of these relocated emissions should be performed both by producers from China and consumers from Japan and Korea.

China, the world's largest emitter, should first take the responsibility to mitigate its huge domestic PM2.5 emission. However, the emission leakages it has suffered from neighboring developed countries should not be ignored. For Japan and Korea, due to the close economic interdependence and geographical position, any contribution to the reduction of the trans-boundary emissions or to the solution of atmosphere problems within China also helps those countries indirectly. In the long run, all three countries would benefit from enhancing subregional environmental cooperation.

\section{What has already been done to mitigate trans-boundary PM2.5?}

The subregional environmental cooperation in East Asia has made valuable achievements. However, countries at different development periods hold different appeals of environmental cooperation. It will still take time to reach a solid and regulatory regime 
with legal force in East Asia. Among all the current multilateral cooperation mechanisms of trans-boundary environmental problems (LTP, TEMM, NEASPEC, EANET), most regulatory mechanisms are still on framework build and research work level. Tangible actions with solid funds to solve trans-boundary PM problems are still lacking.

\section{How to perform reduction responsibility?}

The emission responsibility can be assessed by other means than just the direct bilateral investment perspective. From the financial aspect, it could also be performed in the form of bilateral green aids or loans, such as the official or private holding of offshore green debts, the core fund contributions of NEASPEC, GEF (Global Environment Facility), UNEP (United Nations Environment Programme) or other subregional environmental cooperation mechanisms backed with funds. What's more, NGO projects, multinational corporations' inputs and other cooperation via private channels were also included.

It is widely accepted the establishment of a solid regulatory regime with legal force to deal with trans-boundary environment issues in East Asia could hardly move on due to the intense current relationships. And this paper believes that a powerful trilateral cooperation among China, Japan and Korea could guide a further and wider cooperation among all Asian countries, especially by providing some inspiration of emission reduction pattern for India or Indonesia, who would soon become comparable to China if viewed by their emission trends. This paper also believes that for China, Japan and Korea, trilateral cooperation on an environmental level could inversely improve further trilateral cooperation on economic or political level.

\section{Additional file}

Additional file 1. Integration of sectors from date source GAINS and WIOD.

\section{Acknowledgements}

The author would like to express sincere gratitude to the China Scholarship Council (CSC) for financial support for seeking the doctor degree, as well as the helpful comments from reviewers.

Competing interests

The author declares that there is no competing interests.

Availability of data and materials

The dataset supporting the conclusions of this article is available in DOI: 10.13140/

RG.2.2.33738.57280. Besides, the hyperlink to Appendix is in: https://www.researchgate.net/

publication/315695375_Appendix_Tracking_the_Trans-boundary_PM25_among_China_Japan_and_Korea.

\section{Consent for publication}

Not applicable.

Ethics approval and consent to participate

Not applicable.

Funding

Not applicable.

\section{Publisher's Note}

Springer Nature remains neutral with regard to jurisdictional claims in published maps and institutional affiliations. 


\section{Appendix}

Integration processes of raw data to 16 sectors in this paper please refer to the Additional file 1.

Received: 25 May 2017 Accepted: 9 October 2017

Published online: 27 October 2017

\section{References}

Borge R, Lumbreras J, Vardoulakis S, Kassomenos P, Rodríguez E (2007) Analysis of long-range transport influences on urban PM10 using two-stage atmospheric trajectory clusters. Atmos Environ 41(21):4434-4450

Chen F, Yamashita K, Kurokawa J, Klimont Z (2015) Cost-benefit analysis of reducing premature mortality caused by exposure to ozone and PM2.5 in East Asia in 2020. Water Air Soil Pollut 226(4):108-125. doi:10.1007/s11270-015-2316-7

Dovland H, Ballaman R, Thompson J, Sliggers J, Kakebeeke W (eds) (2004) Clearing the air: 25 years of the convention on long-range transboundary air pollution. United Nations, United Nations Publication, New York, pp 1-6

IIASA (2008a) Gains Asia: a tool to combat air pollution and climate change simultaneously, methodology. International Institute for Applied Systems Analysis, Laxenburg

IIASA (2008b) Gains Asia: scenarios for cost-effective control of air pollution and greenhouse gases in China. International Institute for Applied Systems Analy- sis, Laxenburg

Kanemoto K, Moran D, Lenzen M, Geschke A (2014) International trade undermines national emission reduction targets: new evidence from air pollution. Glob Environ Change 24:52-59

Kim I (2014) Me by the Republic of Korea in regional environmental cooperation on transboundary air pollution issues. Int Environ Agreem Polit Law Econ 14(2):147-162

Kiesewetter G et al (2015) Modelling PM2.5 impact indicators in Europe: health effects and legal compliance. Environ Model Softw 74:201-211. doi:10.1016/j.envsoft.2015.02.022

Klimont Z et al (2016) Global anthropogenic emissions of particulate matter including black carbon. Atmos Chem Phy Discuss 17(4):1-72. http://www.atmos-chem-phys-discuss.net/acp-2016-880/

Lai H, Kawashima H, Shindo J, Ohga K (2001) Stages in the history of China's acid rain control strategy in the light of China-Japan relations. Water Air Soil Pollut 130:1843-1848

Lee S, Ho CH, Lee YG, Choi HJ, Song CK (2013) Influence of transboundary air pollutants from China on the high-PM10 episode in Seoul, Korea for the period October 16-20, 2008. Atmos Environ 77:430-439

Lenzen M, Murray J (2010) Conceptualising environmental responsibility. Ecol Econ 70:261-270

Li M, Zhang Q, Kurokawa J, Woo JH, He KB, Lu Z, Ohara T, Song Y, Streets DG, Carmichael GR, Cheng YF, Hong CP, Huo H, Jiang XJ, Kang SC, Liu F, Su H, Zheng B (2015) MIX: a mosaic Asian anthropogenic emission inventory for the MICSAsia and the HTAP projects. Atmos Chem Phys Discuss 15(23):34813-34869. doi:10.5194/acpd-15-34813-2015.7-673

Mageet SP, Ford WF (1972) Environmental pollution, the terms of trade and balance of payments of the United States. Kyklos 25:101-181

Markusen JR (1975) Cooperative control of international pollution and common property resources. Q J Econ 89(4):618-632

Meng J et al (2015) Tracing Primary PM 2.5 emissions via Chinese supply chains. Environ Res Lett 10(5):54005. http:// www.scopus.com/inward/record.url?eid=2-s2.0-84930225571\&partnerlD=tZOtx3y1

Miller RE, Blair PD (2009) Input-output analysis: foundations and extensions. Cambridge University Press, Cambridge, pp $10-16$

Pethig R (1976) Pollution, welfare and environmental policy in the theory of comparative advantage. J Environ Econ Manag 2:160-169

Siebert H (1977) Environmental quality and the gains from trade. Kyklos 30(4):65

Skelton A, Guan D, Peters GP, Crawford-Brown D (2011) Mapping flows of embodied emissions in the global production system. Environ Sci Technol 45:10516-10523

Spencer J (2007) Why China could blame its $\mathrm{CO}_{2}$ on West. Wall St J. Nov 12 A:2. http://online.wsj.com/article/ SB119482231216689376.html

Sugiyama T et al (2009) Compilation and application of a primary PM 2.5 emissions inventory with high sectoral resolution in Japan. Atmos Environ 43(4):759-768. doi:10.1016/j.atmosenv.2008.11.003

Takahashi K, Nansai K, Tohno S, Nishizawa M, Kurokawa J, Ohara T (2014) Production-based emissions, consumptionbased emissions and consumption-based health impacts of PM2.5 carbonaceous aerosols in Asia. Atmos Environ 97:406-415

Waugh FV (1950) Inversion of the Leontief matrix. Econometrica 18(2):142-154

WHO (2006) WHO air quality guidelines for particulate matter, ozone, nitrogen dioxide and sulfur dioxide. WHO Press, World Health Organization, pp 8-13

Zhao ZQ et al (2017) Mitigating ammonia emission from agriculture reduces PM 2.5 pollution in the Hai River Basin in China. Sci Total Environ 609:1152-1160 